\title{
REMINISCENCES OF BIRD BANDING AT DAVIDSON, SASKATCHEWAN
}

\author{
by Albert C. Lloyd, Carnegie Museum, Pittsburgh
}

After 45 years it is difficult to go back in memory and bring to life the early history of bird-banding at Davidson. My father, Reuben Lloyd, was one of the early settlers of the Davidson District, arriving there in 1904 or 1905 from Illinois. As a boy he had been raised on a farm and had become interested in wild life, mainly the study of birds. Sometime about 1914 , he was offered a male White-tailed Deer that had been captured swimming from one of the islands to the mainland in Last Mountain Lake. This was the start of what later was known as The Lloyd Private Game Peserve, which he maintained throughout his lifetime. The Reserve was located a half-mile north of the town of Davidson and consisted of about five acres surrounded by a nine-foot-high pagewire fence. $\mathrm{H}$ e constructed a low earthen dam across a shallow ravine forming a pond some half-mile long and maybe 200 feet wide at the widest point. This was also included in the reserve and filled each year by the run-off from the melting snow. The pond was a great attraction for migrating and resident birds. In the enclosed part of the Reserve he maintained a small herd of deer and from time to time several Prong-horned
Antelope were kept. Each spring several fawn deer would be born. In 1916 or 1918 the first antelope was born in captivity for which the Dominion Government had any record. The pair of twins were later killed by a hailstorm that passed through the area. I remember there is a published record put out by the Dominion Government along with a picture of my father taken with the twins. Also in this enclosure my father kept Canada Geese, White-fronted Geese and later Blue and Snow Geese, and from time to time, Whistling Swan and numerous species of ducks including Mallards crossed with domesticated English Call Ducks. Many of the ducks were migratory and no attempt was made to keep them through the cold and bitter winter. It was in such surroundings that I spent my early life and received training from my father.

How dull the winter months were back in the twenties and early thirties! Our wintering birds included the Sharp-tailed Grouse, Prairie Chicken, an occasional Snowy Owl and later the Hungarian Partridge. To this list could be added the House Sparrow and the so-called Rock Dove. I cannot help but marvel at the number of wintering birds given by the Blue Jay

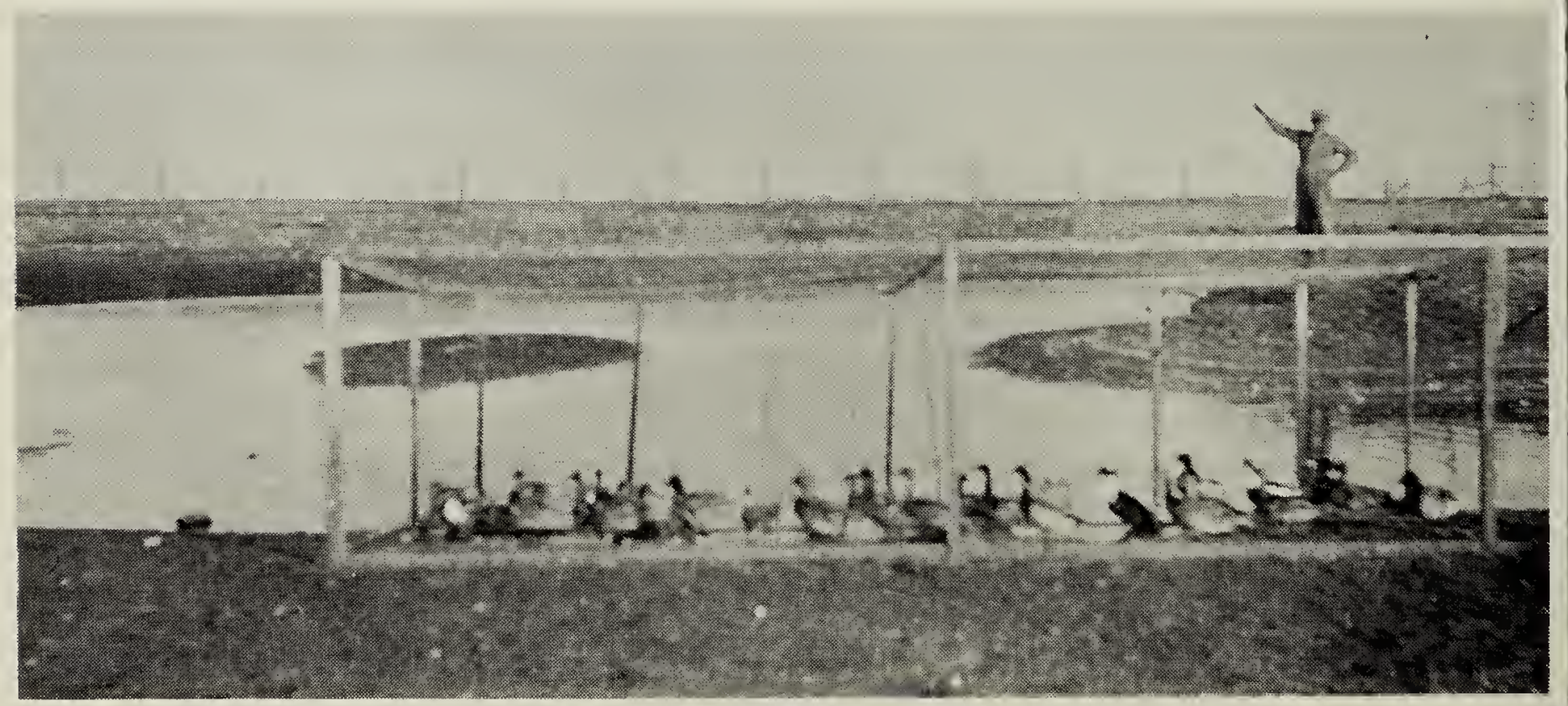

Reuben Lloyd and duck trap at Davidson sanctuary, 1932. 
screen. This was held up by a stick to which a long string was tied. For bait we used weed seed that could be found around any straw stack. When several birds were feeding under the trap, we pulled the string and the stick would be pulled out and the trap dropped over the bird. In one corner of the trap we had a small door that could be opened and a small cage placed so that the bird could be driven into it and be caught.

We soon learned of a better way to use the same trap. Drive a $2 \times 2$ or other wooden stake into the ground leaving about one inch of stick above ground. To this a mouse trap was nailed. Then from this trigger to each back corner of the drop trap we fastened a thread just tight enough so the trap could be set. The prop was then placed on the very edge of the trap so when sprung, the jaw of the mouse trap would knock the stick from under the trap and drop over the bird. This worked very well and we caught many ground-feeding birds this way.

Of course there were other ways we captured adult birds. Sometimes we would catch flickers in their nesting holes in fence posts or telephone poles. Swallows we caught in grain storage bins, grackles in nesting boxes. Once I caught a pair of nesting shrikes by putting a noose on the end of a pole and dropping it over their heads. We also used a lady's hair net by tying two short and one long string to it so that they all joined together. The centre of the net was then fitted into the cup of a nesting bird. A light tug on the long string and you had the bird inside the net. We didn't use this very often since we were afraid of destroying the nest or that the bird might desert the nest.

\section{SASKATCHEWAN BIRD BANDERS*}

\section{REUBEN AND A. C. LLOYD OF DAVIDSON}

\section{by C. Stuart Houston, 863 University Drive, Saskatoon}

Reuben Lloyd began banding birds at Davidson on May 5, 1923. For the first ten years he was assisted by his son Bert, now a Supervisor with the Carnegie Museum in Pittsburgh, Pennsylvania. No birds were banded in 1930, 1933 and 1936 and only two were banded in 1937 .

$\mathrm{His} \log$ book, kindly loaned by his son Albert C. Lloyd, records 3177 individuals of 73 species. At first, bands evidently were not issued in numerical order on wires or strings as they are today, for in the early years Mr. Lloyd applied them in random order-e.g. using number 73, then 62, then 66 .

Some evidently escaped entry in the record book, as banding and recovery data are available on Fish and Wildlife Service printouts or were pub-

* No. 12 in a series of biographies of Saskatchewan bird banders. lished in the Canadian Field-Naturalist, for 14 individuals not recorded in the banding log book. Ten of the 14 were banded in the first year 1923

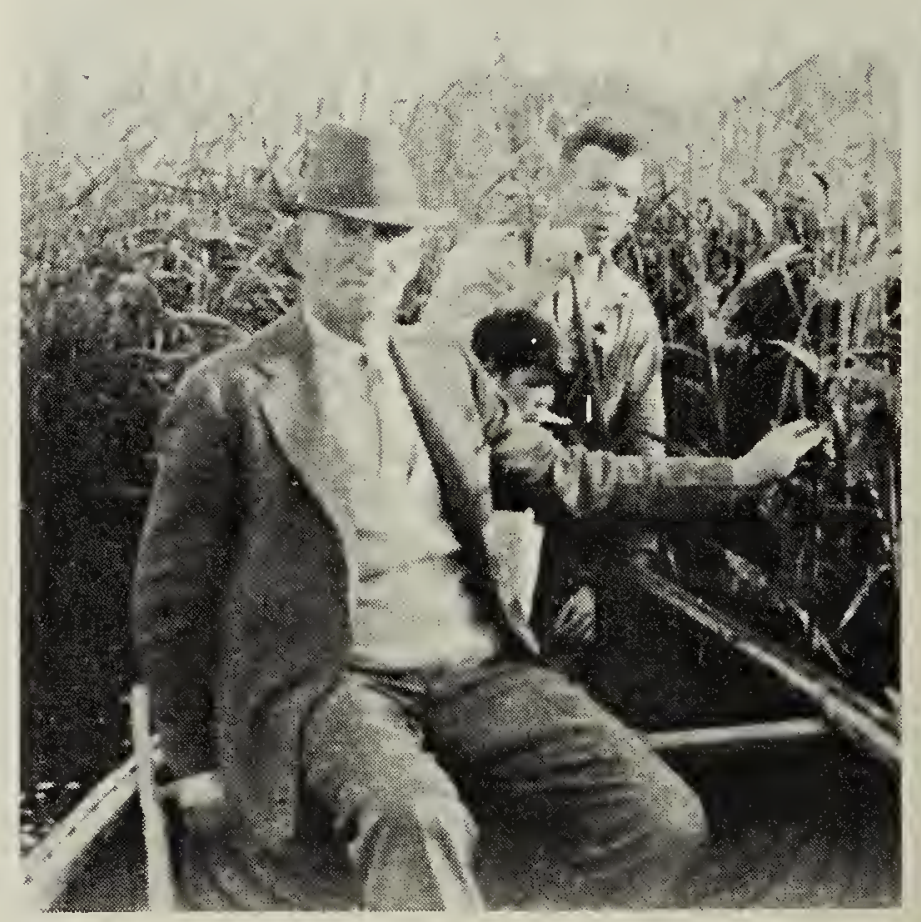

Reuben Lloyd 